\title{
LAS CORTES DE ARAGÓN COMO PARLAMENTO ABIERTO: LOS MECANISMOS DE PARTICIPACIÓN CIUDADANA EN LOS PROCEDIMIENTOS PARLAMENTARIOS*
}

\author{
Cortes de Aragón as Open Parliament: Mechanisms \\ of Citizen Participation in Parliamentary Procedures
}

\author{
Enrique Cebrián Zazurca \\ Profesor de Derecho Constitucional \\ Universidad de Zaragoza \\ ecebrian@unizar.es
}

orcid: http://orcid.org/0000-0001-6239-1420

doi: http://dx.doi.org/10.18543/ed-65(2)-2017pp15-38

Recibido: 29.09.2017

Aceptado: 28.11.2017

\section{Resumen}

El 28 de junio de 2017 el Pleno de las Cortes de Aragón aprobó por unanimidad la Proposición de reforma del Reglamento parlamentario, que sustituye a la regulación de 1997. Entre otras cuestiones, la norma reformada incluye un Título XVIII, que recoge el derecho al Parlamento abierto y establece como principios de su funcionamiento los de transparencia y participación. Este trabajo quiere presentar el

* Cómo citar / Citation 'Chicago-Deusto' (Autor-fecha / Author-date / Lista de referencias / Reference list entries): Cebrián Zazurca, Enrique. 2017. «Las Cortes de Aragón como Parlamento abierto: Los mecanismos de participación ciudadana en los procedimientos parlamentarios». Estudios de Deusto 65, n. ${ }^{\circ}$ 2: 15-38. doi: http://dx.doi. org/10.18543/ed-65(2)-2017pp15-38. 
contenido de este Título, centrándose especialmente en el análisis de los mecanismos de participación ciudadana en procedimientos parlamentarios, recogidos en el artículo 306 del nuevo Reglamento, presentándolos como traducción práctica del debate doctrinal protagonizado por la tríada democracia representativa - participación ciudadana - descentralización política.

\section{Palabras clave}

Parlamento abierto; Reglamento parlamentario; participación ciudadana; Cortes de Aragón; descentralización política.

\section{Abstract}

June 28, 2017 the Plenary Session of the Cortes de Aragón unanimously approved the proposal for reform the parliamentary regulation, which replaces the one of 1997. The reform includes the right to Open Parliament, based on the principles of transparency and participation. This essay focus on the analysis of the mechanisms of citizen participation in parliamentary procedures (article 306), presenting them as practical translation of the doctrinal debate about representative democracy, citizen participation and political decentralization.

\section{Keywords}

Open Parliament; Rules of Parliamentary Procedure; Citizen Participation; Cortes de Aragón; Political Decentralization. 


\begin{abstract}
Sumario: I. Introducción. II. Abriendo el parlamento. III. AMPLIANDO EL CAMPO DE VISIÓN. IV. EL PARLAMENTO ABIERTO EN EL REGLAMENTO DE LAS CORTES DE ARAGÓN. 1. Iniciativa legislativa popular. 2. Participación en el procedimiento legislativo mediante audiencias ciudadanas. 3. Participación en el procedimiento legislativo mediante enmiendas de iniciativa ciudadana. 4. Solicitud de comparecencia ante la comisión de comparecencias ciudadanas y derechos humanos. 5. Presentación de propuestas de preguntas de iniciativa ciudadana. 6. Presentación de propuestas de proposiciones no de ley de iniciativa ciudadana. 7. Foros de participación. 8. Derecho de petición. V. CONCLUSIONES. 1. Un balance de los mecanismos participativos en el Reglamento de las Cortes de Aragón. 2. Más Parlamento, mas Parlamento. 3. Descentralización política y participación ciudadana. BIBLIOGRAFÍA.
\end{abstract}

\title{
I. INTRODUCCIÓN
}

El 28 de junio de 2017 las Cortes de Aragón aprobaron por unanimidad un nuevo Reglamento parlamentario, que sustituye a la anterior regulación de 1997. Aunque la necesidad de reforma y actualización era sentida tiempo atrás (Herráiz Serrano, 2016; Tudela Aranda, 2014: 376), el camino concreto conducente a este resultado había comenzado a andarse formalmente el 7 de octubre de 2015 con la creación de una Ponencia especial formada por un diputado de cada uno de los seis Grupos del Parlamento aragonés, a saber: D. Antonio Torres Millera (Grupo Parlamentario Popular de las Cortes de Aragón), D. Javier Sada Beltrán (Grupo Parlamentario Socialista), D. Héctor Vicente Ocón (Grupo Parlamentario Podemos Aragón), Dña. María Herrero Herrero (Grupo Parlamentario Aragonés), D. José Javier Martínez Romero (Grupo Parlamentario Ciudadanos - Partido de la Ciudadanía (C's)) y Dña. Ana Patricia Luquin Cabello (Grupo Parlamentario Mixto).

Según lo dispuesto en la Disposición Final Primera de la norma aprobada, esta había de entrar en vigor en el período de sesiones siguiente al de la fecha de su publicación, por lo que cuando escribo estas líneas -septiembre de 2017- el nuevo Reglamento está ya vigente.

La intención de este trabajo no es analizar el Reglamento parlamentario aragonés en su totalidad, sino centrarse en la novedad que representa su Título XVIII, denominado «Del Parlamento abierto». Y, aun dentro de este, detenerse de manera específica en los distintos mecanismos de participación ciudadana allí presentes, valorando los instrumentos que se recogen, su regulación, su tradición en el parlamentarismo, si la hubiere, así como las posibles innovaciones y cambios que pueden propiciar. 


\section{ABRIENDO EL PARLAMENTO}

Me parece importante, antes de comentar experiencias y herramientas concretas, exponer mínimamente cuál es la génesis del concepto de Parlamento abierto y qué es lo que entendemos por tal.

Creo no equivocarme al afirmar que el Parlamento abierto es una idea que nace en el punto de intersección de dos realidades: la crisis de la representación política y el desarrollo tecnológico.

Se ha de ser cuidadoso al hablar de la crisis representativa o del parlamentarismo, ya que, debido al excesivo uso de la expresión, esta corre el riesgo de terminar no queriendo decir nada. Y ello, en realidad, como es sabido, por la sencilla razón de que la representación siempre ha estado en crisis, tan solo han ido cambiando los motivos por los que ello sucedía o, dicho de otro modo, las razones de la crisis. Al hablar hoy de crisis hablamos de la última manifestación de una situación ya estable, una manifestación debida a numerosos factores y que hoy se traduce en desafección, desvalorización del Parlamento e impugnación de su esencia, sintetizada en el eslogan que hizo famoso el $15 \mathrm{M}$ y que tiene la virtud de señalar la idea nuclear y de no poder decir más con menos palabras: No nos representan.

Junto a ello, desde finales del siglo XX hasta hoy, el progreso tecnológico ha experimentado una velocidad inusitada y ha puesto en nuestras manos valiosas herramientas que han configurado de un modo distinto nuestra forma de vivir y relacionarnos, la principal de las cuales es sin ninguna duda Internet, herramienta en sí misma y herramienta que sirve para dar sentido a otras (como, por ejemplo, los teléfonos inteligentes).

Presento la idea de Parlamento abierto como algo surgido de la unión de estas dos realidades con la voluntad de ofrecer una imagen lo suficientemente gráfica y expresiva y, aun considerándola válida, pienso que debe afirmarse asimismo que no se trata de dos realidades completamente separadas hasta el momento de coincidir en un punto, sino que, en puridad, la existencia del comentado progreso tecnológico ha servido de algún modo para terminar de dibujar los perfiles de esta actual crisis representativa. Las amplias posibilidades ofrecidas por la tecnología han contribuido a dar mayor relieve a una representación política en estado crítico, aunque es cierto que no siempre de manera justa, puesto que, como también ha ido recordando la literatura científica en estos últimos años, no todo lo posible técnicamente tiene por qué ser deseable desde un punto de vista democrático.

Volviendo a la imagen de ese punto de encuentro entre una representación en crisis y una tecnología en auge es allí donde ha encontrado acomodo la propuesta de hacer de los Parlamentos instituciones más abiertas en lo referente a ofrecer información, actuar de manera transparente y favorecer cauces de participación de los ciudadanos que completen la mera 
participación electoral para elegir a los miembros de las cámaras. Transparencia, colaboración y participación son los tres pilares sobre los que, como recuerda Rafael Rubio, debe levantarse este nuevo edificio (Rubio Núñez, 2014: 401-413). Miguel Ángel Gonzalo sustituye a la colaboración por la rendición de cuentas en su definición del modelo (Gonzalo Rozas, 2016).

Eva Campos ha trazado un interesante recorrido tomando como elemento explicativo la influencia que en las últimas décadas, desde la extensión de Internet, ha operado la innovación tecnológica sobre la institución parlamentaria, partiendo de un modelo que califica de «Parlamento electrónico», pasando por el «Parlamento digital»y habiendo llegado hoy a este «Parlamento abierto», regido por los principios de información y participación (Campos Domínguez, 2014: 35-47).

Hace unos pocos años se escribió de forma colaborativa en la red Novagob una definición de Parlamento abierto que, por desgracia, ya no está disponible en Internet en su fuente original, pero que ha sido reproducida en otros lugares y que considero muy completa, más allá de su desorden gramatical, fruto de la suma de distintas posiciones. Según esta definición, Parlamento abierto sería «aquel que comunica toda la actividad parlamentaria y la información sobre la institución y sus miembros de forma transparente y en formatos abiertos y entendibles por la ciudadanía; que abre espacios de participación y colaboración con los ciudadanos y con los funcionarios; que, en forma de conversación permanente, tiene cauces que incluyen a las redes sociales, para escuchar activamente lo que la ciudadanía necesita al abrir foros deliberativos y otros instrumentos de participación en los procedimientos parlamentarios con capacidad de influir en la agenda política».

El concepto de Parlamento abierto, además de ser hijo de la relación entre crisis representativa y avance tecnológico, posee otra característica relevante. Se trata de un concepto que se propone, si no superar, sí desde luego minimizar la dicotomía entre democracia representativa y democracia directa. Partiendo de una evidente posición representativa -pues no en vano el calificativo abierto acompaña a Parlamento-, se entiende que aquellos mecanismos -tradicionales o novedosos- que impliquen un papel más activo de la ciudadanía deben integrarse en la lógica parlamentaria y no ser vistos como algo ajeno. La relación de los ciudadanos con su Parlamento se convierte en una relación fluida y multidireccional, lejos de la imagen de la cámara como fortín inexpugnable, ajena por lo demás desde un punto de vista teórico a la propia idea original de Parlamento. Como ha escrito el profesor Asensi Sabater: «Aun debiendo prevalecer el principio de la democracia representativa frente a la democracia directa, una parlamentología consecuente, que tenga la pretensión de recuperar la iniciativa frente a los procesos de globalización, no debe situarse en contradicción, sino en coordinación, con los instrumentos participativos de la democracia directa, como 
son la iniciativa popular legislativa y el referéndum, y abrirse hacia otros ámbitos de participación con mayor capacidad deliberativa y capacidad de decisión» (Asensi Sabater, 2002: 47-48). Este entendimiento de la democracia representativa hacia otras formas de participación corrige también, de alguna manera, la mirada reprobatoria con la que la tecnología parecía recriminar al Parlamento, y a la que antes me he referido.

Creo firmemente que una de las cuerdas a las que los Parlamentos pueden asirse para salvarse de naufragios, peligros e irrelevancias es la cuerda de la participación ciudadana, que haría bien en convertirse en una soga fuerte y resistente. Con ella es más fácil corregir las que en otro lugar he expuesto como insuficiencias de la democracia representativa, y que cifro, sin ánimo exhaustivo, en insuficiencias deliberativas, deficiencias en el control político y en la rendición de cuentas e insuficiente receptividad de los representantes (Cebrián Zazurca, 2013: 97-113).

La idea de Parlamento abierto es la que defiende José Tudela cuando habla del «Parlamento necesario» y de la configuración de un «derecho al Parlamento». De hecho, los instrumentos que propone este autor para fomentar la participación son sustancialmente los mismos que ha incluido el Reglamento de las Cortes de Aragón (Tudela Aranda, 2008; Tudela Aranda, 2009).

\section{AMPLIANDO EL CAMPO DE VISIÓN}

Al hablar de ampliar el campo de visión pretendo poner de manifiesto que el Título XVIII del Reglamento de las Cortes de Aragón no es una isla en un océano de Parlamentos «de maza y peluca», en ilustrativa expresión de Tudela (Tudela Aranda, 2008: 334), sino que es un capítulo más de la recién referida historia destinada a abrir los Parlamentos a una mayor participación ciudadana.

En este sentido, sirva como paradigma el caso de la Cámara de Diputados de Brasil, que constituye, a partir de la labor iniciada en 2008 por Cristiano Ferri con la iniciativa E-democracia ${ }^{1}$, uno de los experimentos más significativos de Parlamento abierto: herramientas para llevar a cabo una legislación colaborativa entre ciudadanos y diputados, posibilidad de compartir información, comunidades virtuales, vídeoforos, votaciones inteligentes, audiencias ciudadanas interactivas y en directo, laboratorio hacker, etc. (Ferri Faria, 2013: 195 y ss.; Ferri Faria, 2014).

${ }^{1}$ «El nombre no es muy afortunado porque en nuestro contexto se suele referir más al parlamento electrónico, pero en realidad es una compleja plataforma colaborativa» (Gonzalo Rozas y Cavero Cano, 2013: 18). 
En el marco español, esta voluntad del Parlamento aragonés se ha visto también acompañada de prácticas similares llevadas a cabo por otros Parlamentos autonómicos.

Cataluña fue pionera con la implantación en 1998 de Democràcia.web, una herramienta impulsada por la Fundació Jaume Bofill con el apoyo del Parlament, concebida para establecer, a través de la democracia electrónica, cauces de participación de los ciudadanos catalanes con su Asamblea Legislativa (Colombo Vilarrasa, 2006). En la actualidad existe en la página web del Parlament de Cataluña el llamado Escó 136 (Escaño 136), que permite, tal y como allí se explica, hacer aportaciones, comentarios o sugerencias sobre las proposiciones y los proyectos de ley en tramitación, así como establecer a partir de estas acciones canales de comunicación públicos con los diputados, quedando todo ello al final reflejado en una memoria anexa a las iniciativas tramitadas. De igual modo, se permite efectuar ante el Parlament peticiones electrónicas, en ejercicio del derecho de petición. Y también se incluye un apartado destinado a los grupos de interés, con lo relativo a la normativa que se les aplica y facilitando formularios de registro, la consulta de los grupos registrados, su agenda, etc. Todo ello no es sino la plasmación de lo contenido en el Texto Refundido del Reglamento del Parlament de Cataluña, aprobado en 2015, y que incorpora los principios de transparencia, además de un muy amplio conjunto de herramientas participativas englobadas en el marco del Parlamento abierto (Título VI).

El Reglamento de las Corts Valencianes, en su Título XV bis, denominado «Del Parlamento abierto», establece la creación de la Comisión Permanente no Legislativa Especial de Participación Ciudadana y establece instrumentos para hacer posible la participación ciudadana de los representantes de colectivos sociales, organizaciones y corporaciones de derecho público, de profesionales y expertos de reconocido prestigio, así como de los alcaldes de municipios de la Comunidad Autónoma. Por su parte, el artículo 113 bis del Reglamento habilita a la ciudadanía valenciana, bien directamente o bien por medio de las asociaciones inscritas en el registro correspondiente, así como a los ayuntamientos por acuerdo del Pleno, para presentar enmiendas a las proposiciones y proyectos de ley en tramitación ${ }^{2}$.

El Reglamento del Parlamento de Andalucía prevé en su artículo 112 la consulta a organizaciones sociales y a ciudadanos en el procedimiento legislativo. En su artículo 114 bis permite a los ciudadanos andaluces -siempre a través de las asociaciones inscritas en el registro correspondiente- el presentar, con carácter general, enmiendas al articulado de las proposiciones y proyectos de ley. Además, el artículo 165 de este Reglamento permite a los

${ }^{2}$ Un análisis detallado de la regulación valenciana puede seguirse en Guillem Carrau (2017). 
andaluces, ciudadanos residentes en Andalucía y personas jurídicas con domicilio en esa Comunidad Autónoma el formular por escrito preguntas para respuesta oral dirigidas al Consejo de Gobierno o a cada uno de sus miembros.

El artículo 67.1.f) del Reglamento de la Junta General del Principado de Asturias contempla la comparecencia en Comisión de asociaciones y grupos de interés afectados.

Si nos fijamos en el Reglamento del Parlamento de Canarias, encontramos el artículo 63.1., con el siguiente tenor: «Las Comisiones permanentes podrán acordar solicitar al Pleno la creación de subcomisiones en su seno para la realización de informes sobre asuntos concretos de interés público en materia de su competencia. A tal fin, las subcomisiones que se creen podrán propiciar la audiencia en su seno tanto de ciudadanos como de aquellos colectivos sociales en que estos se organizan». Y el artículo 174 permite a cualquier ciudadano residente en Canarias presentar por escrito preguntas para ser respondidas oralmente, dirigidas al Gobierno de Canarias o a cualquiera de sus miembros; en una línea similar a la andaluza, pero con una importante excepción en el caso canario: no podrá haber preguntas dirigidas al Presidente del Gobierno de Canarias.

En el caso de Galicia, ha sido la Ley 7/2015, de 7 de agosto, de iniciativa legislativa popular y participación ciudadana en el Parlamento de Galicia la que ha introducido mecanismos como la participación popular en la elaboración de las leyes, en el impulso de la acción de gobierno a través de proposiciones no de ley y en el control al Gobierno.

El Reglamento de la Asamblea de Extremadura incorpora en su artículo 85 la posibilidad de crear Intergrupos Parlamentarios, que puedan «promover el contacto entre los miembros del Parlamento y la sociedad». El artículo 93.1. f) del Reglamento recoge la posibilidad de comparecencia en Comisión de ciudadanos y grupos de interés. Comparecencia de organizaciones y, excepcionalmente, de ciudadanos también contemplada como posibilidad una vez celebrado el debate de totalidad (artículo 164). Asimismo, este Reglamento de la Asamblea de Extremadura constituye en el seno de la misma el Consejo Extremeño de Ciudadanos y Ciudadanas (artículo 271), como foro de consulta para la participación ciudadana, siguiendo lo establecido en el artículo 38 de la Ley 4/2013, de 21 de mayo, de Gobierno Abierto de Extremadura, que creaba el citado Consejo.

El Reglamento de la Asamblea de la Ciudad Autónoma de Ceuta recoge en su artículo 91 el derecho de cualquier persona física o jurídica a dirigir preguntas a la Mesa de la Asamblea, con el ruego de que sean formuladas a algún miembro del Consejo de Gobierno.

Y el Reglamento de la Asamblea de la Ciudad Autónoma de Melilla cuenta con un artículo 65.3., que se limita a afirmar que «la participación de 
los ciudadanos en las Comisiones y en el Pleno de la Asamblea se regulará en un reglamento de participación ciudadana».

Algunas Asambleas autonómicas han aprobado códigos éticos y de conducta de sus parlamentarios, como es el caso de la catalana, siguiendo un mandato de su Reglamento; de la canaria, como parte del más amplio «Plan de Transparencia del Parlamento de Canarias 2015-2019» (Gonzalo Rozas, 2017a); o de la castellano-manchega.

Como análisis de conjunto, en lo que respecta a la calidad de sus páginas web, y sin dejar de reconocer que queda margen importante de mejora, ya en 2014 se podía extraer como conclusión que nuestras cámaras territoriales «han realizado importantes esfuerzos para acercarse a los criterios reconocidos internacionalmente, proporcionando a los ciudadanos una considerable cantidad de información acerca de sus funciones, estructura y funcionamiento, en formato de libre acceso y descarga, contribuyendo así al fomento de la transparencia en sus actividades diarias» (Ramos Vielba, Silván, Stan y Polo, 2014: 317). La importancia creciente de las redes sociales en estos últimos años se ha visto reflejada también en el aumento y mejora de los perfiles institucionales de los Parlamentos y también de los parlamentarios individuales. La página web del Parlamento Vasco incluye, desde 2006, la herramienta Parte Hartu (Participar), establecida como un canal de diálogo entre los ciudadanos y los Grupos Parlamentarios. Parte Hartu convive con Zabalik (Abierto), una suscripción gratuita para recibir por correo electrónico con carácter semanal información relativa a los temas de trabajo del Parlamento. A Parte Hartu y Zabalik se suma ADI! (acrónimo de Aporta, Debate e Influye), un espacio para mantener discusiones sobre temas de actualidad y sobre proyectos y proposiciones de ley, permitiendo también comentar las aportaciones de otros participantes y votar. Tras cada proceso de debate se elabora un documento en el que aquel queda reflejado, junto con las iniciativas más destacadas; documento que es trasladado a los parlamentarios para que puedan tener en cuenta, si así lo consideran, las opiniones ciudadanas a la hora de presentar enmiendas y de votar. Junto al $A D I$ ! generalista existe otro más específico $A D I$ ! $B A K E A$, que se presenta, en términos literales, como «un espacio de participación ciudadana para reflexionar en torno a la paz y la convivencia, sobre la base del acuerdo del Parlamento y de la Ponencia de Paz y Convivencia». Por su parte, el Parlamento de Navarra cuenta con una página web dedicada al Parlamento abierto, en la que se puede deliberar, aportar y opinar acerca de los textos legislativos en tramitación. La web del Parlamento cántabro incorpora una plataforma de acceso on line de participación ciudadana y discusión de iniciativas legislativas. La del Parlamento de La Rioja permite trasladar a los Grupos Parlamentarios opiniones y aportaciones sobre los proyectos de ley en tramitación. Y, recientemente, a través de la web de las Cortes de Castilla y León, se ha incorporado la posibilidad 
de que los ciudadanos realicen aportaciones a iniciativas legislativas, así como a iniciativas de impulso y control de la acción del Gobierno.

Como puede verse, la apertura creciente de los Parlamentos a la ciudadanía parece que será una nota característica de la institución en este comienzo y mediados del siglo XXI; no obstante, y sin desmerecer lo que de positivo hay en que existan unas webs parlamentarias a la altura de estas circunstancias, considero que el elemento verdaderamente relevante y diferenciador es el de contener o no los principios del Parlamento abierto en el propio Reglamento de la cámara, en tanto que expresión del principio de autonormatividad parlamentaria.

En esta misma línea de ampliación del campo de visión, y sin salir ahora del marco aragonés, la inclusión de los principios del Parlamento abierto en el Reglamento de sus Cortes autonómicas se encuentra en sintonía con una voluntad de profundización democrática que atañe también al Ejecutivo y a la Administración Pública, guiados cada vez más por los principios del llamado Gobierno abierto. La Ley aragonesa 8/2015, de 25 de marzo, de Transparencia de la Actividad Pública y Participación Ciudadana de Aragón camina por esa senda, recogiendo para este ámbito algunos instrumentos de participación similares a los que ahora están presentes en el Reglamento de las Cortes de Aragón (RCA). Una mención merece asimismo la Ley 5/2017, de 1 de junio, de Integridad y Ética Públicas. Y el propio Estatuto de Autonomía de Aragón (EAAr) recoge en su artículo 15 el derecho de participación, en el 20 la obligación de los poderes públicos de facilitar la participación política, económica, cultural y social y en el 30 un mandato destinado a los poderes públicos encaminado a promover una cultura de participación y de valores democráticos.

\section{EL PARLAMENTO ABIERTO EN EL REGLAMENTO DE LAS CORTES DE ARAGÓN}

Como antes se ha adelantado, el nuevo Reglamento de las Cortes de Aragón cuenta con un Título -el XVIII (artículos 300 a 311)- destinado a integrar el concepto de Parlamento abierto en la norma reguladora de la organización y el funcionamiento de la cámara ${ }^{3}$.

El Título se abre con un Capítulo que, bajo la rúbrica de «Disposiciones generales», recoge en primer lugar el derecho de los ciudadanos a un Parlamento abierto (artículo 300), para a continuación (artículo 301) especificar

${ }^{3}$ Recién aprobado el RCA se publicaron en dos blogs unos primeros y sintéticos análisis de las novedades que se introducían en materia de Parlamento abierto y participación; me refiero a Gonzalo Rozas (2017b) y Asociación para la defensa de la función pública aragonesa (2017). 
cuáles son los principios del Parlamento abierto en las Cortes aragonesas. Estos se concretan en dos: el principio de transparencia y el principio de participación. Aunque ambos son tenidos en cuenta habitualmente para medir la apertura de un Parlamento, y guardan relación entre sí, en este trabajo me centro en la vertiente participativa del Parlamento abierto. Considero que esta es la que puede resultar más interesante, en la medida en que puede incorporar mejoras y modificaciones de mayor calado, puesto que un Parlamento podría llegar a ser absolutamente transparente en cuanto a derecho de acceso de los ciudadanos, publicidad de su actividad, etc. sin por ello haber tenido que cambiar ni un ápice de su funcionamiento interno. Por este motivo, en el análisis concreto de este Título XVIII continuaré atendiendo a la vertiente participativa del Parlamento abierto. Así, la letra b) del antedicho artículo 301 RCA afirma, en aclaración del proclamado principio de participación, que «las Cortes de Aragón promoverán el uso por los ciudadanos de los instrumentos de participación en los procedimientos parlamentarios previstos en el presente Reglamento, así como el ejercicio adecuado de su derecho de petición y de acceso a la información». Tras un Capítulo II, centrado en esa otra vertiente de transparencia parlamentaria, nos encontramos con el Capítulo III, denominado «De la participación ciudadana en la actividad parlamentaria». Este arranca con el artículo 305, en el que se recoge un derecho de participación ciudadana para cuya puesta en práctica se concede un papel relevante a la página web de las Cortes de Aragón y a las posibilidades que, según el Reglamento, la misma tendrá que ofrecer: planteamiento de iniciativas, sugerencias y aportaciones, posibilidad de contactar con Diputados y Grupos Parlamentarios o conocer la tramitación y el estado en el que se encuentran esas iniciativas llevadas a cabo y, en general, cualquier iniciativa parlamentaria.

Es el artículo 306 RCA el que va a concretar los derechos y principios del Título XVIII en una variedad de mecanismos a través de los cuales los ciudadanos van a poder participar en los procedimientos parlamentarios.

Se trata de los siguientes:

\section{Iniciativa legislativa popular}

El artículo 306.1.a) RCA recoge este mecanismo de participación, que habrá de ponerse en práctica «de acuerdo con lo dispuesto en su normativa reguladora».

El derecho a presentar iniciativas legislativas populares ante las Cortes de Aragón encuentra su fundamento y desarrollo en los artículos 15.2. y 42.2. EAAr, 159 RCA y en la Ley 7/2014, de 25 de septiembre, de modificación de la Ley 7/1984, de 27 de diciembre, reguladora de la iniciativa legislativa popular ante las Cortes de Aragón. Esta Ley introduce cambios importantes 
con respecto a la anterior regulación proveniente de los primeros años de autogobierno en Aragón, unos cambios que van en la dirección, como afirma el Preámbulo de la norma, «de facilitar el uso de la iniciativa legislativa popular a los ciudadanos y de propiciar una democracia más participativa» y que son deudores en buena medida de las propuestas y reflexiones llevadas a cabo por la profesora Eva Sáenz Royo en la «Mesa de expertos para la definición de la política normativa del Gobierno de Aragón en materia de participación ciudadana», creada en el año 2009 (Saénz Royo, 2010: 46-61) ${ }^{4}$. En la norma de 2014 se amplían las materias que pueden ser objeto de esta iniciativa legislativa popular (ILP); se reduce de quince a doce mil el número de firmas exigidas, se amplía el plazo para recabarlas y se contempla que puedan ser firmas electrónicas; se eliminan requisitos para la presentación de la iniciativa; se establece la obligación de su debate en la misma Legislatura y se facilita la compensación económica a los promotores.

No obstante, a pesar de la voluntad de profundización democrática de la nueva regulación, sigue siendo válido en líneas generales -como no podía ser de otra forma, atendida la naturaleza de este instituto de participación política- el análisis que Manuel Contreras hacía de la regulación anterior, destacando como característica doble de la ILP en Aragón su carácter complementario de la representación y su equilibrio entre la representación surgida de un proceso electoral democrático y el establecimiento de un cauce que permita una participación asimismo democrática (Contreras Casado, 1986: 84-85).

Debe destacarse que Aragón es una de las Comunidades Autónomas en las que más veces se ha puesto en marcha este instrumento participativo hasta en nueve ocasiones- y también una de las pocas en las que una proposición de iniciativa legislativa popular llegó a convertirse en ley, siendo el primer caso en España (Cuesta López, 2008: 369-408; Contreras Casado, 2014: $129(\text { nota 25) })^{5}$.

\section{Participación en el procedimiento legislativo mediante audiencias ciudadanas}

El artículo 306.1.b) RCA incorpora esta forma de participación política, que habrá de llevarse a cabo de acuerdo con lo dispuesto en el artículo 163 del Reglamento. Si atendemos a la regulación de este, vemos cómo, una vez

${ }^{4}$ Algunos de los instrumentos participativos introducidos en el actual Reglamento de las Cortes de Aragón también habían sido propuestos en el Informe elaborado para esta Mesa de expertos por la profesora Sáenz Royo.

${ }^{5}$ Fue la Ley 2/1992, de 13 de marzo, de creación del Consejo de Protección de la Naturaleza. 
celebrado el debate de totalidad, los Diputados y los Grupos Parlamentarios disponen de un plazo de cinco días para proponer por escrito a la Mesa de la Comisión «la audiencia de los agentes sociales, organizaciones y ciudadanos que pudiesen estar interesados en la regulación de que se trate, incluidas, en su caso, las Administraciones públicas». Se parte del presupuesto de que los comparecientes serán representantes de colectivos sociales afectados, siendo excepcional que puedan ser personas a título individual las que comparezcan. También se incorpora la posibilidad de que sean las entidades representativas de los entes locales, en los casos de proyectos o proposiciones de ley que afecten a estos. El número de las comparecencias será acorde y proporcional a la importancia numérica de los Grupos Parlamentarios que las hayan propuesto. Una vez que la Comisión lo comunica a quienes han de comparecer, hay un plazo de diez días para celebrar la audiencia, que deberá tener lugar ante al menos un representante de cada Grupo o Agrupación Parlamentaria de la Comisión de que se trate. El apartado sexto del artículo detalla el procedimiento que habrá de seguirse en estas audiencias públicas: «En cada comparecencia, en primer lugar, intervendrán los comparecientes durante un tiempo de quince minutos $\mathrm{y}$, posteriormente, los grupos parlamentarios podrán formular preguntas o solicitar aclaraciones durante un tiempo de cinco minutos. La comparecencia concluirá con la contestación de los comparecientes a las cuestiones planteadas durante un tiempo de cinco minutos. Con carácter excepcional, cuando los términos del debate así lo aconsejen, la Presidencia podrá conceder a los grupos parlamentarios un turno adicional por un tiempo máximo de dos minutos»».

El artículo $71.27^{\mathrm{a}}$. EAAr recoge, entre las competencias exclusivas de la Comunidad Autónoma, la organización de audiencias públicas.

De la regulación del Reglamento parlamentario aragonés se puede extraer, como conclusión principal, que los sujetos en los que se piensa como protagonistas de estos hearings ${ }^{6}$ son los grupos de interés y solo, de manera excepcional, los ciudadanos individuales. Esto es lo habitual en este tipo de herramientas de participación (el artículo 15 de la Ley 7/2015 del Parlamento de Galicia constituye una excepción a esta regla); y es lo habitual ya que «estos grupos actúan en interés de la comunidad, ya sea por representar determinados intereses que se estiman como colectivamente relevantes o por ser expertos en la materia de que se trate» (Aja Fernández y Larios Paterna, 1998: 80). Sin embargo, no siempre debe caerse en una visión tan complaciente de los mismos, por lo que son necesarias alertas para impedir que lo que se presenta como un instrumento participativo y de mejora legislativa

${ }^{6}$ Un panorama acerca de cómo se recogen estos hearings o audiencias en el funcionamiento de distintos Parlamentos nacionales puede encontrarse en Presno Linera (2012: 104-105). 
termine dando lugar a la contaminación interesada de la producción normativa de los representantes de la ciudadanía. Por ello, se echa en falta en el RCA la referencia a un registro de asociaciones, como se hace en otros casos de Derecho comparado. Asimismo, el Reglamento del Parlamento aragonés carece de unas reglas claras en cuanto a las mayorías necesarias para que una comparecencia salga o no adelante ${ }^{7}$.

En cualquier caso, es de celebrar la incorporación de este instrumento, puesto que viene a aportar claridad y seguridad jurídica a prácticas que, de facto, se han producido siempre ${ }^{8}$. Cuando no existe legislación, los grupos se ven obligados «a actuar de manera informal lo que determina que el acceso a las instancias parlamentarias se produzca de una manera desigual, primando fundamentalmente criterios como el de las relaciones de amistad o conveniencia» (Rubio Núñez, 2003: 291). Es por este motivo por el que la regulación de la actividad de los grupos en sede parlamentaria ofrece importantes ventajas en el ámbito de la publicidad, el pluralismo político, la transparencia y el control; no solo en contraposición a la costumbre no regulada, sino también en comparación con otras prácticas, como la participación de los grupos en sede gubernativa en la fase prelegislativa (Aja Fernández y Larios Paterna, 1998; Sáenz Royo, 2010; Tudela Aranda, 2008: 242; Tudela Aranda, 2010: 80; Rubio Núñez, 2003: 292).

\section{Participación en el procedimiento legislativo mediante enmiendas de iniciativa ciudadana}

El artículo 306.1.b) RCA también introduce, con una voluntad de mejora democrática de las leyes del Parlamento, esta posibilidad, de acuerdo con el artículo 165 del Reglamento de la Cámara. Este artículo 165 reconoce a cualquier persona física o representante de persona jurídica residente en Aragón el derecho a registrar propuestas de enmienda motivadas al articulado de los proyectos de ley en los diez primeros días del plazo general de presentación de enmiendas. La presentación se hará por escrito en el registro General de

${ }^{7}$ «Pero la cuestión verdaderamente importante es la de quién y cómo decide sobre la oportunidad de las comparecencias. (...) Dejar la decisión sobre la celebración efectiva de las comparecencias a los citados órganos [se refiere a la Comisión correspondiente o a la Mesa o a la Junta de Portavoces] supone en la práctica dejar esa decisión a la mayoría, lo cual es, a su vez, dejarla en manos del gobierno. Una vez más, parece que el juego se repite. El Parlamento se desapodera de hecho y la minoría queda relegada a las sombras de las Cámaras», en Tudela Aranda (2013: 107).

${ }^{8}$ La transparencia y la publicidad actúan también como medios para garantizar que el Parlamento acaba cumpliendo su defensa del interés general frente al peligro de que su papel pudiera llegar a ser colonizado por distintos intereses particulares (Tudela Aranda, 2013: 112). 
las Cortes de Aragón o a través de la página web de la cámara, con la necesaria identificación. Finalizado el plazo de presentación, las propuestas podrán ser asumidas en un plazo de tres días por, al menos, un Grupo o Agrupación Parlamentaria y serán presentadas como enmiendas al proyecto de ley en tramitación, debiendo constar en su motivación su origen en una iniciativa ciudadana. El artículo 165 RCA concluye con un apartado cuarto con el siguiente tenor: « $\mathrm{Si}$, como resultado de los trabajos de la Ponencia, el autor de una propuesta de enmienda ciudadana considera que se ha desvirtuado su contenido, podrá ponerlo de manifiesto por escrito ante la Ponencia en cualquier momento previo a la votación en Pleno, lo que no supondrá la retirada de la transacción realizada, en su caso.

Incorporadas estas enmiendas de iniciativa ciudadana, se echa en falta que la posibilidad de su presentación no se haya extendido a las proposiciones de ley, tratándose de una ausencia que no acaba de estar en consonancia con el espíritu del nuevo Reglamento y que, más que contemplar y alentar prácticas participativas, parece preferir el poner un celo excesivo e innecesario en la autoprotección de la institución parlamentaria.

\section{Solicitud de comparecencia ante la Comisión de Comparecencias Ciudadanas y Derechos Humanos}

El artículo 306.1.c) RCA establece que los ciudadanos podrán participar en los procedimientos parlamentarios mediante la solicitud de comparecencia ante la Comisión de Comparecencias Ciudadanas y Derechos Humanos. Más allá del cambio de denominación de la Comisión -antes se llamaba «Comisión de Peticiones y Derechos Humanos»- operado por el nuevo Reglamento, la posibilidad de comparecer ante esta Comisión Permanente de las Cortes de Aragón (artículo 77. b) RCA) ya existía con anterioridad. El 306.1.c) señala que se hará «de acuerdo con lo dispuesto en el artículo 81 de este Reglamento». A su vez, el artículo 81.1. establece que esta Comisión tramitará las solicitudes de comparecencia de representantes de colectivos sociales, personas físicas o representantes de personas jurídicas de acuerdo con lo estipulado por el RCA. Y, según el artículo 75.3. del Reglamento, estas solicitudes serán calificadas por la Mesa de las Cortes, que las trasladará a la Comisión de Comparecencias Ciudadanas y Derechos Humanos, aunque también se establece aquí la posibilidad de que sean trasladadas a otra Comisión en función de su competencia por razón de la materia. Es el artículo 242 RCA el que, por su parte, regula el procedimiento para la sustanciación de la comparecencia, estableciendo en su apartado segundo que «se iniciará con la exposición del compareciente por un tiempo máximo de quince minutos. A continuación intervendrán los grupos parlamentarios por un tiempo máximo de cinco minutos. La comparecencia concluirá con la 
contestación del compareciente a las cuestiones planteadas durante un tiempo máximo de diez minutos. Con carácter excepcional, cuando los términos del debate así lo aconsejen, la Presidencia podrá conceder a los grupos parlamentarios un turno adicional por un tiempo máximo de dos minutos». Esta regulación contenida en el artículo 242.2. RCA supone, en este punto, una novedad, en comparación con el artículo 56.5. del anterior Reglamento, que se limitaba a afirmar que estas comparecencias «serán reguladas por Resolución de la Presidencia, oída la Junta de Portavoces». Existía una Resolución de la Presidencia de las Cortes de Aragón, de 29 de septiembre de 2000 , sobre la comparecencia de representantes de colectivos sociales, personas físicas o representantes de personas jurídicas, cuyo artículo $4^{\circ} .1$. establecía lo siguiente: «Estas comparecencias tendrán carácter meramente informativo, por lo que su sustanciación se limitará a una intervención de treinta minutos, en la que se expondrán a la Comisión las razones de la comparecencia». Sin embargo, por respeto y como muestra de interés hacia los comparecientes, este procedimiento nunca fue puesto en marcha. En su lugar, se articuló un modelo basado en un primer turno de los comparecientes, un turno posterior de intervención de los Grupos Parlamentarios de menor a mayor y un turno final de respuesta de los comparecientes, variando, de una a otra Legislatura, los tiempos de cada uno de esos turnos. Puede verse, por tanto, que el nuevo RCA establece como norma lo que venía siendo una práctica parlamentaria, fijando, a su vez, como tiempos concretos de los turnos los empleados en la actual Legislatura.

\section{Presentación de propuestas de preguntas de iniciativa ciudadana}

El artículo 306.1.d) RCA recoge este mecanismo participativo, que habrá de ser ejercido «en los términos previstos en el artículo 266 de este Reglamento». Este artículo 266 regula estas preguntas de iniciativa ciudadana. Ya antes el artículo 259.2. había afirmado que «los ciudadanos residentes en Aragón podrán formular propuestas de preguntas, de acuerdo con lo previsto en el artículo 266». Lo primero que debe destacarse es que se tratará de preguntas dirigidas únicamente al Gobierno de Aragón, en tanto que las propuestas de preguntas ciudadanas se equiparan a las preguntas de los parlamentarios destinadas al Gobierno como medio clásico de ejercicio de la función parlamentaria de control del Ejecutivo. Estas pueden ser formuladas por cualquier persona física o representante de persona jurídica residentes en Aragón. Deben presentarse por escrito, con la preceptiva identificación, en el Registro General del Parlamento o a través de su página web. Las preguntas serán examinadas por la Mesa de la Cámara y, si cumplen los requisitos exigidos, serán admitidas a trámite, trasladándose a los distintos Grupos Parlamentarios y publicándose en el Boletín Oficial de las Cortes de Aragón. Para 
ser tramitadas, habrán de ser admitidas por un Diputado en un plazo máximo de quince días a contar desde la fecha de su admisión. El Diputado debe comunicar a la Mesa su voluntad de formularla para respuesta bien oral, bien escrita, y el órgano, en su caso, ante el que pretende su tramitación. Si fueran varios los Diputados interesados en una misma pregunta para respuesta oral, el artículo 266 RCA establece que será asignada al primero que manifieste su voluntad de asumirla. En el caso de que la propuesta de pregunta sea asumida en plazo por un Diputado para su tramitación escrita, la Mesa de la cámara la remitirá al Gobierno de Aragón. Si la tramitación es para respuesta oral, el Diputado deberá hacer constar en su intervención el autor de la iniciativa y no podrá modificar sustancialmente su contenido. Aquellas preguntas admitidas a trámite por la Mesa, pero no asumidas, en el plazo marcado, por ningún Diputado se considerarán decaídas. Por último, una vez finalizado un período de sesiones, aquellas propuestas de preguntas orales asumidas en plazo por un Diputado, pero que no hayan podido ser sustanciadas en Pleno o Comisión, se tramitarán como preguntas para respuesta por escrito.

Resulta muy interesante este mecanismo participativo, en tanto que cubre una de las funciones del Parlamento, como es la función de control. Digo esto porque, habitualmente, al hablar de mecanismos de participación ciudadana, se tiende a pensar sobre todo en la función legislativa de las cámaras. Y, sin embargo, abrir las puertas a la participación puede provocar efectos beneficiosos en una función tan básica como la de control al Gobierno (arts. 33.1. EAAr y 1 RCA). Siendo esto así, estimo que no habría estado de más el recoger también en el Reglamento, como herramienta diferenciada con presupuestos y finalidades distintas, la posibilidad de presentar propuestas de preguntas de iniciativa ciudadana, dirigidas no al Gobierno de Aragón, sino a cualquier Diputado de las Cortes. Se trataría no de ejercer la función de control, sino de establecer un diálogo entre los ciudadanos y los parlamentarios. Una suerte de control, si se quiere, pero entendido de una manera amplia y dirigido por los ciudadanos hacia sus representantes políticos, con carácter e impacto público, en la sede parlamentaria y más allá de la comunicación que pueda establecerse a través, por ejemplo, del correo electrónico.

\section{Presentación de propuestas de proposiciones no de ley de iniciativa ciudadana}

El artículo 306.1.e) RCA contempla esta herramienta de participación, que habrá de ejercerse «en los términos previstos en el artículo 270 de este Reglamento». Antes, el artículo 267.2. ya había afirmado que «los ciudadanos residentes en Aragón podrán formular propuestas de proposiciones no de ley, de acuerdo con lo previsto en el artículo 270». El artículo 270 habilita a cualquier persona física o jurídica residente en Aragón para formular 
propuestas de proposiciones no de ley, a través de las cuales formulen propuestas de resolución a la cámara. Aquellas habrán de presentarse por escrito en el Registro General de las Cortes de Aragón, o bien a través de su página web, y habrán de contener los necesarios requisitos identificativos. Serán examinadas por la Mesa y, si cumplen las exigencias pertinentes, se ordenará su traslado a los Grupos Parlamentarios y se publicarán en el Boletín Oficial de las Cortes de Aragón. Es necesario que sean asumidas por un Grupo o Agrupación Parlamentaria para que puedan tramitarse en Pleno o Comisión y tendrán que ser presentadas como proposición no de ley en un plazo máximo de quince días a contar desde la fecha de su admisión. El Grupo o Agrupación que haya asumido la propuesta debe comunicar a la Mesa el órgano ante el que pretende su tramitación. Las propuestas admitidas a trámite por la Mesa pero no asumidas en plazo por Grupo o Agrupación alguna se considerarán decaídas. El artículo 270 RCA exige asimismo que se haga constar en la proposición no de ley la autoría de la iniciativa, impidiendo en su formulación inicial modificaciones sustanciales de su contenido originario.

No existe en el caso de Aragón ninguna regulación equivalente a la que contiene el artículo 16.2. b) de la Ley gallega 7/2015, que requiere 2.500 firmas para suscribir una proposición no de ley de iniciativa popular.

Las proposiciones no de ley, en tanto que «propuestas de resolución de carácter no legislativo que se someten a debate y votación de la Cámara, y que sirven para que ésta manifieste su voluntad, deseo o aspiración» (Contreras Casado, 2014: 139), no son «propiamente un instrumento de control de la acción, sino de la inacción o de lo que se entiende que es una acción inadecuada del Gobierno en relación con un determinado asunto» (Pérez Royo, 2014: 657). El artículo 274 RCA establece diversos mecanismos de control del cumplimiento de las proposiciones no de ley aprobadas. A pesar de la que el profesor Presno denuncia como «inoperancia, más allá de la instantánea parlamentaria, de este tipo de iniciativas» (Presno Linera, 2016), lo cierto es que, mientras entendamos que hay situaciones en las que las proposiciones no de ley pueden jugar una función de impulso político por parte del Parlamento (Contreras Casado, 2016: 139), la posibilidad de que los ciudadanos tengan derecho a presentar propuestas en esta dirección debe ser considerada de manera positiva desde una perspectiva participativa exigente.

\section{Foros de participación}

Tras haber presentado los mecanismos participativos que se acaban de analizar, el artículo 306 RCA incluye un apartado segundo, en el que se afirma: «De igual modo, las Cortes de Aragón promoverán foros de participación para el diálogo, la reflexión o el estudio sobre las materias 
relacionadas con las políticas públicas de la Comunidad Autónoma y la actividad de la Cámara».

Ya el artículo 71.27 . EAAr había establecido entre las competencias exclusivas de la Comunidad Autónoma la habilitación de foros de participación.

Se trata de una redacción la del Reglamento de la cámara lo suficientemente general como para permitir su puesta en práctica de muy diversas maneras, lejos del corsé de una única y estricta formulación. Sus objetivos y temas podrán ser variados, podremos encontrarnos ante foros de debate y análisis presenciales o en línea, podrá decidirse cuál es la forma de determinar quiénes serán los participantes, etc. Pienso que esta versatilidad no debe, en ningún caso, conducir a la creencia de que se trata de instrumentos de importancia menor. A pesar de que su traducción en la práctica parlamentaria más inmediata puede ser menos visible que la de otros instrumentos, ello no quiere decir que su puesta en funcionamiento no sea capaz de generar una rentabilidad en términos de deliberación pública y de reflexión colectiva de gran utilidad para la sociedad aragonesa y su Parlamento.

En otro lugar me he detenido de manera extensa en la presentación de un posible modelo de foros participativos (Cebrián Zazurca, 2012) y algunas de las ideas allí propuestas quizás puedan servir de guía para los introducidos por el artículo 306.2. RCA.

Estos foros pueden contribuir, además, a un mejor desempeño de las funciones parlamentarias, especialmente de aquellas que no son las clásicas, pero que van adquiriendo un mayor protagonismo en la actualidad, como puedan ser las funciones de información política, de estudio o de pedagogía democrática (Tudela Aranda, 2008: 159-192).

\section{Derecho de petición}

El derecho de petición no se encuentra recogido en este artículo 306 RCA que venimos analizando, sino en el Capítulo IV y último del Título XVIII. Este Capítulo - titulado «Del derecho de petición»-comprende de los artículos 307 a 311 . No aparece, por lo tanto, categorizado como un mecanismo de participación ciudadana, pero estimo no obstante que así debe ser entendido desde una concepción participativa amplia y en línea con la interpretación que el Tribunal Constitucional hizo en su Sentencia 242/1993 al afirmar que este derecho «tiene un mucho de instrumento para la participación ciudadana, aun cuando lo sea por vía de sugerencia, y algo del ejercicio de la libertad de expresión como posibilidad de opinar» (Fundamento Jurídico Primero).

La extensa y detallada redacción actual presenta una novedad importante con respecto a la magra regulación del artículo 62 del anterior Reglamento y viene a dar un más ajustado cumplimiento a la Disposición Adicional 
Primera de la Ley Orgánica 4/2001, de 12 de noviembre, reguladora del Derecho de Petición cuando afirma: «Las peticiones dirigidas al Congreso de los Diputados, al Senado o a las Asambleas Legislativas de las Comunidades Autónomas se tramitarán de conformidad a lo establecido en sus respectivos Reglamentos que deberán recoger la posibilidad de convocar en audiencia especial a los peticionarios, si así se considera oportuno...»».

\section{CONCLUSIONES}

\section{Un balance de los mecanismos participativos en el Reglamento de las Cortes de Aragón}

Algunas de las herramientas de participación que se han visto ya existían y son instituciones clásicas y otras constituyen verdaderas novedades, pero el integrar todas conjuntamente bajo las rúbricas de Parlamento abierto y participación ciudadana aporta una idea de coherencia y una visión de conjunto. Además, el actual Reglamento supone la constatación de que, en muy pocos años, se ha ido imponiendo entre las distintas fuerzas políticas una visión más participativa de la vida parlamentaria y más proclive, en definitiva, a este concepto de Parlamento abierto. Muestra de ello es el hecho de que en 2013 se registró una Proposición de reforma del RCA, que no siguió adelante por falta de consenso. La profesora y Letrada de las Cortes de Aragón Olga Herráiz ha estudiado detenidamente el contenido de aquella Proposición y nos recuerda que «una de las ausencias que resultó decisiva de la falta de acuerdo final para aprobar la proposición de reforma fueron las audiencias ciudadanas en el procedimiento legislativo aunque también mayores herramientas de participación directa en el Parlamento (por ejemplo, pudiendo presentar enmiendas al articulado de proyectos y proposiciones de ley vía $w e b$, que serían tramitadas si fueran asumidas por algún grupo parlamentario)...» (Herráiz Serrano, 2016: 115). Podemos ver, en consecuencia, aun sin triunfalismos y sin obviar lo que queda por mejorar, que el camino se va andando en la dirección de la apertura y la participación; no en vano, como se ha podido comprobar, el Reglamento de las Cortes de Aragón contempla

9 Se afirma en el blog de la Asociación para la Defensa de la Función Pública Aragonesa lo siguiente a este respecto: «No es preciso recordar que esta Asociación a lo largo de sus diez años de actividad ha ejercido una constante acción ciudadana ante el Parlamento aragonés, a través del derecho de petición -negado en dos ocasiones por la Mesa de las Cortes y motivo de amparo por el Tribunal Constitucional, en una sentencia que necesariamente se ha debido tener presente a la hora de reformar su reglamento-...» (se refiere a la STC 108/2011, de 20 de junio) (Asociación para la defensa de la función pública aragonesa, 2017). 
una de las regulaciones más amplias en el ámbito español en lo relativo a la inclusión de mecanismos participativos.

\section{Más Parlamento, mas Parlamento}

Nótese antes de proseguir que en el título de este punto conviven, en un muy simple juego de palabras, un determinante o cuantificador y una conjunción adversativa. Lo que con ello se quiere indicar es que el concepto de Parlamento abierto propugna la necesidad de fomentar la relevancia del mismo, a través de un fortalecimiento de sus funciones y de un acercamiento a la ciudadanía, pero que, a la vez y por ello, no se trata de sustituir la definición esencial de qué cosa sea una cámara parlamentaria; sino, en todo caso, de perfeccionarla, ampliarla y revitalizarla. Quiere construirse un mejor Parlamento, no sustituir su caracterización básica por otra radicalmente diferente. Esto quiere decir que el Parlamento sigue cumpliendo la labor -por medio del mecanismo de la representación política- de crear la voluntad de una comunidad (Cebrián Zazurca, 2013: 73-91). Se pretende que la expresión de esa voluntad, a través de las distintas funciones asignadas al Parlamento, se lleve a cabo de una mejor manera, gracias a la participación y al diálogo con la ciudadanía. Pero ese diálogo y esa participación no pueden llegar al extremo de sustituir a los parlamentarios y a la institución en el ejercicio de los cometidos que jurídicamente tienen asignados, lo que al cabo produciría una erosión democrática. Dicho de otro modo, el sujeto que toma las decisiones y que lleva a cabo las acciones sigue siendo el mismo, como se ha visto, pero puede verse asistido por una ciudadanía que ejerce de manera activa sus derechos de participación, lo cual le ayudará a cumplir sus funciones de un modo más exigente desde el punto de vista de la calidad democrática.

El modelo de Parlamento abierto se propone difuminar en parte la frontera entre el espacio no institucionalizado y el espacio institucionalizado, acercando el primero al ámbito del segundo. Operando con las categorías habermasianas de facticidad y validez (Habermas, 1998), se trataría de establecer una comunicación entre la opinión pública y la institución parlamentaria, con la intención de que esta se nutra de aquella. Se necesita más Parlamento para que siga existiendo hoy verdadero Parlamento. Se necesita más Parlamento pero que siga existiendo hoy verdadero Parlamento.

\section{Descentralización política y participación ciudadana}

Si observamos la realidad española, es un hecho que son las Asambleas autonómicas (aunque no todas, ni con la misma intensidad) las que, en sus Reglamentos y en sus sitios web, están innovando e incorporando los elementos principales del Parlamento abierto a su funcionamiento y 
organización. Como ha escrito Pérez Alberdi, «los fenómenos de descentralización política ofrecen un marco más adecuado a las fórmulas de la Democracia participativa y, por ello, puede constatarse un creciente desarrollo legislativo de las fórmulas de participación ciudadana en los distintos niveles institucionales de distribución territorial del poder político» (Pérez Alberdi, 2008: 184).

Pero, a pesar de lo que el autogobierno supone de acercamiento del poder a los ciudadanos y de facilitación de la participación de estos en aquel, nada impide, desde un punto de vista teórico y axiológico, que cámaras como el Congreso de los Diputados o el Senado se abran a los principios y mecanismos aquí vistos. Para ello, invirtiendo la que fue la tendencia general en los primeros años de construcción del Estado autonómico, pueden ser las distintas experiencias territoriales las que hoy marquen la pauta a las Cortes Generales en la definición de modelos de Parlamento abierto.

\section{BIBLIOGRAFÍA}

Aja Fernández, Eliseo y Larios Paterna, María Jesús (1998): «Parlamentos autonómicos y participación popular. La participación de los grupos sociales en la elaboración parlamentaria de las leyes», en Corts: Anuario de Derecho Parlamentario, núm. 6, pp. 79-100.

Asensi SABATER, José (2002): «La reanimación del Parlamento: exigencia de un «constitucionalismo consecuente»», en Corts: Anuario de Derecho Parlamentario, núm. 12, pp. 29-51.

ASOCIACIÓN PARA LA DEFENSA DE LA FUNCIÓN PÚBLICA ARAGONESA (2017): Nuevas vias de participación ciudadana en la actividad parlamentaria de las Cortes de Aragón, en https://asocfuncionpublica.blogspot.com.es/2017/07/nuevas-vias-departicipacion-ciudadana.html?m=1 (página visitada el 6 de septiembre de 2017).

CEBrián ZaZurca, Enrique (2012): Deliberación en Internet. Una propuesta de modelo de participación política, Zaragoza: Fundación Manuel Giménez Abad de Estudios Parlamentarios y del Estado Autonómico.

- (2013): Sobre la democracia representativa. Un análisis de sus capacidades e insuficiencias, Zaragoza: Prensas de la Universidad de Zaragoza.

Campos Domínguez, Eva (2014): «Historia, concepto y evolución del Parlamento 2.0», en Rubio Núñez, Rafael (Coord.), Parlamentos abiertos. Tecnología y redes para la democracia, Madrid: Cuadernos del Congreso de los Diputados.

Colombo Vilarrasa, Clelia (2006): Democràcia.web, una experiència de democràcia electrònica a Catalunya. Informe d'avaluació, en http://www.fbofill.cat/publicacions/democraciaweb-una-experiencia-de-democracia-electronica-catalunya-informe-davaluacio (página visitada el 6 de septiembre de 2017).

CONTRERAS CASADO, Manuel (1986): «Iniciativa legislativa popular y estado democrático de derecho (una aproximación a su regulación jurídica en España)», en Revista de las Cortes Generales, núm. 8, pp. 67-94. 
(2014): «Las Cortes de Aragón», en Embid Irujo, Antonio (Dir.), Derecho Público Aragonés, $5^{\text {a }}$ edición, Zaragoza: El Justicia de Aragón.

Cuesta LóPEZ, Víctor (2008): Participación directa e iniciativa legislativa del ciudadano en democracia constitucional, Cizur Menor (Navarra): Thomson - Civitas - Parlamento de Canarias.

FERRI FARIA, Cristiano (2013): The open parliament in the age of internet, Brasilia: Edições Câmara.

- (2014): Construyendo el parlamento abierto: el caso de Brasil, en http://www. parlamericas.org/uploads/documents/article-cristiano-ferri-es.pdf (página visitada el 6 de septiembre de 2017).

Gonzalo Rozas, Miguel Ángel (2016): «Transparencia, participación ciudadana y rendición de cuentas en el parlamento», en: Contreras Casado, Manuel y Cebrián Zazurca, Enrique (Eds.), La crisis contemporánea de la representación política, Zaragoza: Comuniter.

— (2017a): Códigos éticos y códigos de conducta: buenas prácticas en gobernan$z a$, en http://miguelgonzalo.net/codigos-de-conducta-para-los-diputados/ (página visitada el 6 de septiembre de 2017).

- (2017b): Parlamento abierto en las Cortes de Aragón, en http://miguelgonzalo. net/parlamento-abierto-las-cortes-aragon/ (página visitada el 6 de septiembre de 2017).

Gonzalo Rozas, Miguel Ángel y CAVEro CANo, Gonzalo (2013): Iniciativas de los parlamentos para promover la participación ciudadana: buenas prácticas, en http://www.gigapp.org/administrator/components/com_jresearch/files/publications/G08-GONZALO_CAVERO-2013.pdf (página visitada el 6 de septiembre de 2017).

Guillem CARRAU, Javier (2017): «Las enmiendas de participación ciudadana: su inserción en el procedimiento legislativo ordinario de Les Corts Valencianes», en Asamblea. Revista parlamentaria de la Asamblea de Madrid, núm. 36, pp. 115-138.

HABERMAS, Jürgen (1998): Facticidad y validez. Sobre el derecho y el Estado democrático en términos de teoría del discurso, Madrid: Trotta.

Herráiz SERrANo, Olga (2016): «La reforma non nata de 2013 como base de los actuales trabajos de revisión del Reglamento de las Cortes de Aragón», en Cuadernos Manuel Giménez Abad, núm. 12, pp. 72-120, en http://www.fundacionmgimenezabad.es/images/Documentos/Cuadernos/cuadernos_12_diciembre2016. pdf (página visitada el 6 de septiembre de 2017).

PÉREZ AlBERDI, María Reyes (2008): «Los derechos de participación en los Estatutos de Autonomía reformados recientemente. (Especial consideración al Estatuto de Autonomía para Andalucía)», en Revista de Derecho Político, núm. 73, pp. 181-205.

PÉrez Royo, Javier (2014): Curso de Derecho Constitucional, 14 a edición (revisada y puesta al día por Carrasco Durán, Manuel), Madrid: Marcial Pons.

PRESNO LinerA, Miguel Ángel (2012): «La participación ciudadana en el procedimiento legislativo como parte de la esencia y valor de la democracia», en Asamblea. Revista parlamentaria de la Asamblea de Madrid, núm. 27, pp. 85-119.

(2016): «Las proposiciones no de ley y otras cosas del querer», en Agenda Pública (20 de octubre de 2016), en http://agendapublica.elperiodico.com/las-pro- 
posiciones-no-de-ley-y-otras-cosas-del-querer/ (página visitada el 6 de septiembre de 2017).

Ramos Vielba, Irene; Silván, Aitor; Stan, Loredana y Polo, Patricia (2014): «¿Hacia parlamentos autonómicos 2.0? Un balance comparado», en: Rubio Núñez, Rafael (Coord.), Parlamentos abiertos. Tecnología y redes para la democracia, Madrid: Cuadernos del Congreso de los Diputados.

Rubio NúÑEZ, Rafael (2003): Los grupos de presión, Madrid: Centro de Estudios Políticos y Constitucionales.

- (2014): «Knocking on the Parliaments Door (Parlamentos digitales en la era de la participación)», en Rubio Núñez, Rafael (Coord.), Parlamentos abiertos. Tecnología y redes para la democracia, Madrid: Cuadernos del Congreso de los Diputados.

SÁENZ Royo, Eva (2010): «Informe sobre las posibles modificaciones normativas en la Comunidad Autónoma de Aragón para fomentar la participación ciudadana en la elaboración de la ley», en Deliberación. Revista para la mejora de la calidad democrática, núm. 1, pp. 43-69.

Tudela Aranda, José (2008): El Parlamento necesario. Parlamento y democracia en el siglo XXI, Madrid: Congreso de los Diputados.

- (2009): «Parlamento, ciudadanía y democracia representativa», en VV. AA., Participación Ciudadana ...para una Administración deliberativa, Zaragoza: Gobierno de Aragón.

(2010): «Parlamento y política legislativa en materia de participación ciudadana», en Deliberación. Revista para la mejora de la calidad democrática, núm. 1, pp. 71-87.

- (2013): «Participación en el procedimiento parlamentario de elaboración de la ley», en Bermejo Latre, José Luis y Castel Gayán, Sergio (Eds.), Transparencia, participación ciudadana y Administración pública en el siglo XXI, Monografías de la Revista Aragonesa de Administración Pública, núm. XIV, pp. 93-119.

(2014): «Las Cortes de Aragón», en Bermejo Vera, José y López Ramón, Fernando (Dirs.), Tratado de Derecho Público Aragonés, Cizur Menor (Navarra): Civitas - Thomson Reuters. 